\title{
Influence of Intercalation-Exfoliation-Reduction Technique towards the Physico-Chemical of VPO Catalysts
}

\author{
Y. C. Wong, ${ }^{1,2}$ and Y. H. Taufiq-Yap ${ }^{2,3}$ \\ ${ }^{1}$ Faculty of Agro Based Industry, Universiti Malaysia Kelantan, Jeli Campus, Locked Bag 100, 17600 Jeli, \\ Kelantan Darul Naim, Malaysia \\ ${ }^{2}$ Centre of Excellence for Catalysis Science and Technology, Universiti Putra Malaysia, 43400 Serdang, Selangor Darul Ehsan, Malaysia \\ ${ }^{3}$ Department of Chemistry, Faculty of Science, Universiti Putra Malaysia, 43400 Serdang, Selangor Darul Ehsan, Malaysia
}

Correspondence should be addressed to Y. C. Wong; yeeching@umk.edu.my

Received 20 December 2011; Revised 21 April 2012; Accepted 22 April 2012

Academic Editor: Fateme Rezaei

Copyright (c) 2013 Y. C. Wong and Y. H. Taufiq-Yap. This is an open access article distributed under the Creative Commons Attribution License, which permits unrestricted use, distribution, and reproduction in any medium, provided the original work is properly cited.

Four VPO catalysts were synthesized through intercalation and exfoliation in various alcohols and subsequent reduction of the exfoliated $\mathrm{VOPO}_{4}$ sheets with various alcohols to produce $\mathrm{VOHPO}_{4} \cdot 0.5 \mathrm{H}_{2} \mathrm{O}$. The resulting $\mathrm{VOHPO}_{4} \cdot 0.5 \mathrm{H}_{2} \mathrm{O}$ that undergoes the intercalation-exfoliation-reduction (IER) process will be further activated into VPO catalysts, and addition of 1 mole \% $\mathrm{Bi}\left(\mathrm{NO}_{3}\right)_{3} \cdot 5 \mathrm{H}_{2} \mathrm{O}$ in the first stage of this experiment has also being investigated. The synthesized materials were characterized by X-ray diffraction (XRD), scanning electron microscope (SEM), transmission electron microscope (TEM), and temperatureprogrammed reduction (TPR) in $\mathrm{H}_{2}$. Catalytic evaluation of the IER-treated and Bi-doped VPO catalysts was also studied on microreactor. The VPO catalyst produced through IER using 2-butanol and ethanol with addition of Bi, IERC(2Bu-Et)RBil, gave the highest MA selectivity due to reactive $\mathrm{O}^{2-}$ species released from the additional crystalline $\mathrm{V}^{5+}$ phase formed by doping $1 \%$ bismuth as promoter $\left(\mathrm{O}^{2-}-\mathrm{V}^{5+}\right.$ pair) at relative lower temperature. Nevertheless, the VPO catalyst produced through IER using isobutanol, IERC(isoBu), gave the highest activity due to high amount of reactive $\mathrm{O}^{-}$species released from $\mathrm{V}^{4+}$ phase $\left(\mathrm{O}^{-}-\mathrm{V}^{4+}\right.$ pair) whereby the IERC(isoBu) catalyst synthesized consists of high percentage of $\mathrm{V}^{4+}(93 \%)$.

\section{Introduction}

Although the selective oxidation of $n$-butane to maleic anhydride (MA) has been commercialised using vanadyl pyrophosphate $(\mathrm{VO})_{2} \mathrm{P}_{2} \mathrm{O}_{7}$ as a catalyst [1-3], low selectivity toward MA remains a serious problem. Therefore, it is keenly desirable to develop new and functional forms of $(\mathrm{VO})_{2} \mathrm{P}_{2} \mathrm{O}_{7}$ that can offer improvements to this oxidation process [4] by using different approach of synthesis method such as intercalation-exfoliation-reduction (IER) technique.

The MA selectivity in this reaction is sensitive to the chemical and physical properties of $(\mathrm{VO})_{2} \mathrm{P}_{2} \mathrm{O}_{7}$ crystallites, including microstructure, defect sites, composition, oxidation state, and the presence of $\mathrm{VOPO}_{4}$ phases [5-7]. Among these factors, the microstructure (shape and dimension) of the $(\mathrm{VO})_{2} \mathrm{P}_{2} \mathrm{O}_{7}$ crystallites is considered to have a critical effect on selectivity in $n$-butane oxidation [5]. Thus, control of the shape and dimension of $(\mathrm{VO})_{2} \mathrm{P}_{2} \mathrm{O}_{7}$ crystallites should result in improved catalytic performance.

In this study, the $\mathrm{VOPO}_{4} \cdot 2 \mathrm{H}_{2} \mathrm{O}$ which is a starting material for the dihydrate route will be intercalated and exfoliated in various alcohols and subsequent reduction of the exfoliated $\mathrm{VOPO}_{4}$ sheets with alcohol to produce $\mathrm{VOHPO}_{4} \cdot 0.5 \mathrm{H}_{2} \mathrm{O}$. The resulting $\mathrm{VOHPO}_{4} \cdot 0.5 \mathrm{H}_{2} \mathrm{O}$ that undergoes the intercalation-exfoliation-reduction (IER) process will be further activated into $(\mathrm{VO})_{2} \mathrm{P}_{2} \mathrm{O}_{7}$ catalysts, and the physic chemical characteristic of this VPO catalysts obtained via this method was examined.

\section{Experimental}

2.1. Preparation of Intercalation-Exfoliation-Reduction (IER) VPO Catalysts. Vanadyl phosphate dihydrate, $\mathrm{VOPO}_{4} \cdot 2 \mathrm{H}_{2} \mathrm{O}$ was synthesized by reacting $\mathrm{V}_{2} \mathrm{O}_{5}(12.0 \mathrm{~g}$ from Fluka) with 
ortho $-\mathrm{H}_{3} \mathrm{PO}_{4}\left(57.4 \mathrm{~cm}^{3}, 85 \%\right.$ from Merck) in distilled water $\left(288 \mathrm{~cm}^{3}\right)$ and under reflux at $393 \mathrm{~K}$ with continuous stirring for $24 \mathrm{~h}$. The colour of the solid solution changed slowly from brownish to yellow. The resultant yellow solid $\left(\mathrm{VOPO}_{4} \cdot 2 \mathrm{H}_{2} \mathrm{O}\right.$ phase) was then recovered by using centrifuge technique and subsequently washed sparingly with distilled water and acetone and oven dried at $373 \mathrm{~K}$ for $24 \mathrm{~h}$.

The well synthesized of $\mathrm{VOPO}_{4} \cdot 2 \mathrm{H}_{2} \mathrm{O}(2.0 \mathrm{~g})$ was suspended by rapid stirring into 2-butyl alcohol $\left(50 \mathrm{~cm}^{3}\right.$ from $\mathrm{BDH}$ ) and was refluxed stepwise at $303,323,343$, and $363 \mathrm{~K}$ for $1 \mathrm{~h}$ at each temperature, yielding a homogeneous, yellow solution as the result of the intercalation, and exfoliation of $\mathrm{VOPO}_{4} \cdot 2 \mathrm{H}_{2} \mathrm{O}$.

Ethyl alcohol $\left(14.4 \mathrm{~cm}^{3}\right.$ from Sigma-Aldrich) was then added at room temperature to the homogeneous 2-butyl alcohol solution, and the solution was refluxed for $24 \mathrm{~h}$ at $393 \mathrm{~K}$ to give a blue precipitate. The precipitate was separated using centrifugation, washed with acetone and oven dried at $353 \mathrm{~K}$ for $24 \mathrm{~h}$, and this catalyst precursor was denoted as $\operatorname{IERP}(2 \mathrm{Bu}-\mathrm{Et})$.

Addition of 1 mole $\% \mathrm{Bi}\left(\mathrm{NO}_{3}\right)_{3} \cdot 5 \mathrm{H}_{2} \mathrm{O}$ in the first stage of this experiment has also being investigated, and the precursor produced was denoted as IERP(2Bu-Et)RBil.

For another section of experiment, the precursor was also prepared by replacing 2-butyl alcohol with isobutyl alcohol, and the precursor produced was denoted as IERP(isoBuEt).

A precursor was also prepared using similar method in first section of this experiment by replacing 2-butyl alcohol with isobutyl alcohol, and followed by the thermal treatment without adding ethyl alcohol and the precursor produced was denoted as IERP(isoBu).

The entire precursor obtained was calcined in reaction flow of $0.75 \% n$-butane/air mixture for $18 \mathrm{~h}$ at $733 \mathrm{~K}$ to generate the active catalyst denoted as IERC(2Bu-Et), IERC(2BuEt)RBi1, IERC(isoBu-Et), and IERC(isoBu).

2.2. Catalysts Characterization. The total surface area of the catalysts was measured by the Brunauer-Emmett-Teller (BET) method using nitrogen adsorption at $77 \mathrm{~K}$. This was done by a Sorptomatic 1990 Series, Thermo-FischerScientific instrument.

The bulk chemical composition was determined by using a sequential scanning inductively coupled plasma-atomic emission spectrometer (ICP-AES) (Perkin Elmer Emission Spectrometer model plasma 1000).

The average oxidation numbers of vanadium in the sample bulk were determined by redox titration following the method of Niwa and Murakami [8].

$\mathrm{X}$-ray diffraction (XRD) analysis was carried out by using a Shimadzu diffractometer model XRD 6000.

The electron microscopy techniques were used to obtain the information on the morphology and size of the samples by LEO 1455 Variable Pressure scanning electron microscope (SEM). The morphology was studied at an accelerating voltage of $30 \mathrm{kV}$. The particles were attached on an aluminium stub by using double-sided tape. The preparation was covered by using a thin layer of gold coating by using BIO-RAD
Sputter Coater. The SEM micrographs were recorded by using a digital camera at various magnifications.

The particle size of the samples was examined using LEO 912AB energy filter transmission electron microscope (TEM) with an acceleration voltage of $120 \mathrm{keV}$.

$\mathrm{H}_{2}$-TPR analysis was performed using ThermoFisher Scientific TPDRO 1100 apparatus equipped with a thermal conductivity detector (TCD). The experiment was done by following the thermal conductivity of the outlet stream with TCD when raising the temperature of the fresh catalysts was raised from ambient to $1223 \mathrm{~K}$ at $10 \mathrm{~K} / \mathrm{min}$ in a $\mathrm{H}_{2} /$ Ar stream.

The oxidation of $n$-butane was carried out at $673 \mathrm{~K}$ with $\mathrm{GHSV}=2400 \mathrm{~h}^{-1}$ in a fixed-bed microreactor with a standard mass of catalyst $(250 \mathrm{mg}) . n$-Butane and air were fed to the reactor via calibrated mass flow controllers to give a feedstock composition of $1.0 \% n$-butane in air. The products were then fed via heated lines to an online gas chromatograph for analysis. The reactor comprised a stainless steel tube with the catalyst held in place by plugs of quartz wool. A thermocouple was located in the centre of the catalyst bed.

\section{Results and Discussions}

3.1. X-Ray Diffraction (XRD). The XRD patterns (Figure 1) of the VPD precursors obtained via intercalation-exfoliationreduction technique are perfectly matched with the standard $\mathrm{VOHPO}_{4} \cdot 0.5 \mathrm{H}_{2} \mathrm{O}$ (JCPDS File no. 37-0269). The main characteristic peaks at $2 \theta=15.6^{\circ}, 19.6^{\circ}, 24.3^{\circ}, 27.1^{\circ}$, and $30.4^{\circ}$ are corresponding to (001), (101), (021), (121), and (130) planes, respectively.

The intercalation-exfoliation-reduction method basically does not cause any changes, in terms of the basic matrix of the vanadyl hydrogen phosphate hemihydrate precursor $\left(\mathrm{VOHPO}_{4} \cdot 0.5 \mathrm{H}_{2} \mathrm{O}\right)$, which could be evidenced from the standard $\mathrm{VOHPO}_{4} \cdot 0.5 \mathrm{H}_{2} \mathrm{O}$ of the JCPDS. Peak at $30.4^{\circ}$ appeared to be the most prominent peak for $\operatorname{IERP}(2 \mathrm{Bu}-\mathrm{Et})$, IERP(isoBu-Et), and IERP(isoBu). This was the main identity of the VPD precursor via the reduction of $\mathrm{VOPO}_{4} \cdot 2 \mathrm{H}_{2} \mathrm{O}$, which could also be observed in other open literatures $[9,10]$. However, the (001) diffraction plane for catalyst precursor IERP $(2 \mathrm{Bu}-\mathrm{Et}) \mathrm{RBil}$ appeared to be more intense and narrower as compared to the others. Therefore, this had indicated that by doping $1 \%$ of bismuth had somehow induced the formation of more crystalline VPD precursor than the other precursor.

Another interesting point to note is that, by changing the solvent from 2-butanol to isobutanol in the intercalation and exfoliation stage, the (001), (101), (021), and (121) appeared to be less intense and broader as compared to those catalysts precursor that using 2-butanol as solvent in the mentioned stage above. Therefore, this also indicated that using isobutanol instead of 2-butanol as solvent in the intercalation and exfoliation stage somehow promotes the formation of more amorphous VPD precursor compared to the VPD precursor that used 2-butanol as solvent in the intercalation and exfoliation stage which has been well studied by Kamiya and coworkers [11]. 


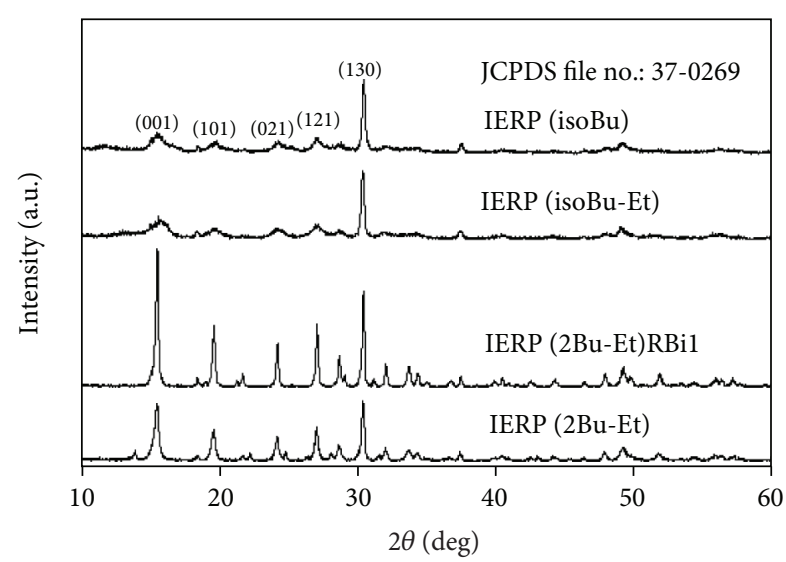

FIGURE 1: XRD patterns for IER-VPD precursors.

Figure 2 exhibited the XRD patterns of intercalationexfoliation-reduction VPD catalysts, after being activated at $733 \mathrm{~K}$ in reaction environment $(0.75 \% n$-butane/air mixture) for $18 \mathrm{~h}$. All the catalysts produced are very similar and show the characteristic of $(\mathrm{VO})_{2} \mathrm{P}_{2} \mathrm{O}_{7}$ phase with (020), (204), and (221) lines at $22.9^{\circ}, 28.4^{\circ}$, and $29.9^{\circ}$, respectively. This particular phase has been accepted to be responsible for the partial oxidation of $n$-butane to maleic anhydride $[2,3]$. However, IERC $(2 \mathrm{Bu}-\mathrm{Et})$ catalyst whereby its precursor prepared through the intercalation-exfoliation-reduction technique using 2-butanol and ethanol shows lower-intensity characteristic peaks of $(\mathrm{VO})_{2} \mathrm{P}_{2} \mathrm{O}_{7}$ phase, which further suggest that this catalyst may consist of lower crystallinity and the formation of more amorphous phase.

Two additional weak peaks emerged at $2 \theta=21.5^{\circ}$ and $29.1^{\circ}$ after addition of bismuth as dopant into the precursor of the catalyst, which corresponds to $\beta-\mathrm{VOPO}_{4}$ (JCPDS File no. 37-0948) and $\alpha_{I I}-\mathrm{VOPO}_{4}$ (JCPDS File no. 34-1247) phases, respectively. This had indicated that the addition of $1 \%$ bismuth as dopant into the precursor catalyst has promoted the formation of $\mathrm{V}^{5+}$ phase component in the catalyst during the calcination stage whereby the precursor of the catalyst topotactically transformed into the active VPO catalyst which is well-agreed with the findings by TaufiqYap and coworkers [12]. Coulston and co-workers [13] reported that the formation of MA is proportional to the rate of $\mathrm{V}^{5+}$ species decay. So, it is believe that the additional formation of $\mathrm{V}^{5+}$ phases in $1 \%$ bismuth-doped IER-VPD catalyst will increase the selectivity towards MA compared to other catalysts.

\subsection{BET Surface Area Measurements and Chemical Analysis.} Table 1 exhibited the total surface areas and chemical analysis results of intercalation-exfoliation-reduction catalysts by using different solvent. The total surface area of IERC $(2 \mathrm{Bu}-$ Et) catalyst which undergoes the intercalation and exfoliation process using 2-butanol and ethanol as reducing agent is only $11.7 \mathrm{~m}^{2} \mathrm{~g}^{-1}$. However, the surface area obtained is differing from the findings by Kamiya and co-workers [11] using the same technique which has total surface area of $46.0 \mathrm{~m}^{2} \mathrm{~g}^{-1}$.

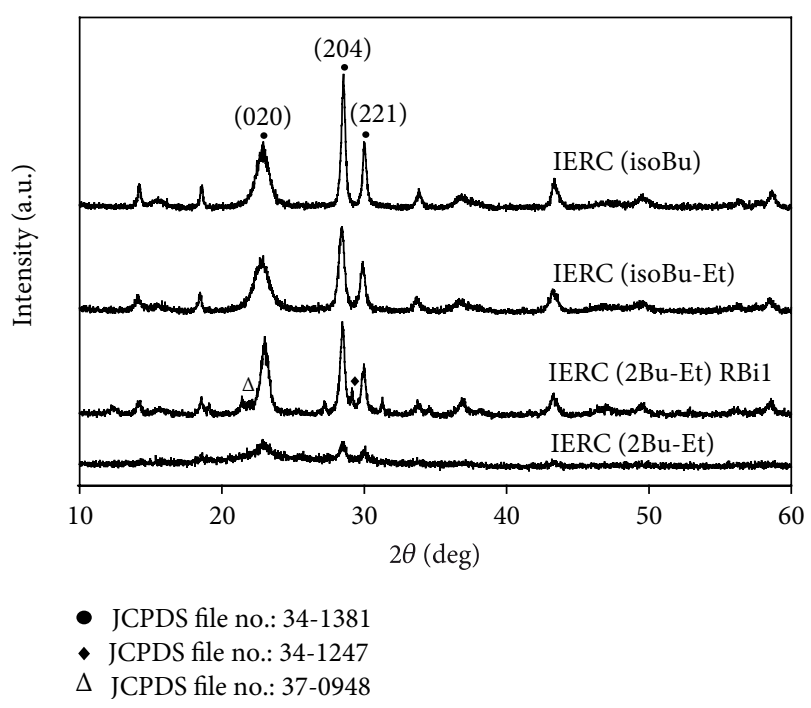

FIGURE 2: XRD patterns for IER-VPD catalysts.

The reduction of surface area may be due to the morphologies shown in the SEM micrograph (following section), indicated that the crystal plates formed in the IERC $(2 \mathrm{Bu}-$ Et) catalyst are relatively small and unstable and have the tendency to agglomerate with each others to form larger platelet that caused lower surface to volume ratio being exposed to the environment.

The surface area of $1 \%$ bismuth-doped IER-VPD catalyst using mixture of 2-butanol and ethanol shown to slightly increase to $15.3 \mathrm{~m}^{2} \mathrm{~g}^{-1}$. The addition of bismuth as dopant into the IER-VPD catalyst has somehow altered the development of the basal (100) $(\mathrm{VO})_{2} \mathrm{P}_{2} \mathrm{O}_{7}$ face which is the interesting feature of the high total surface area of the catalyst produced [12].

Interestingly, changing the reducing agent from 2-butanol to isobutanol with the present of ethanol, IERC(isoBuEt) for intercalation-exfoliation-reduction of $\mathrm{VOPO}_{4} \cdot 2 \mathrm{H}_{2} \mathrm{O}$ drastically increased the total surface area to $35.6 \mathrm{~m}^{2} \mathrm{~g}^{-1}$ approximately 3 times higher than IERC $(2 \mathrm{Bu}-\mathrm{Et})$. However, for IERC(isoBu) catalyst produced in the same technique but without the presence of ethanol has caused slightly decrease in the total surface area to $21.8 \mathrm{~m}^{2} \mathrm{~g}^{-1}$. This may be due to the structures of isobutanol that somehow intercalated the layered $\mathrm{VOPO}_{4}$ sheets much larger compared to 2-butanol and followed by well exfoliated of $\mathrm{VOPO}_{4}$ sheets that formed smaller platelets that caused higher surface to volume ratio being exposed to the environment that directly increased the surface area of the catalysts produced.

Chemical analysis using ICP in Table 1 indicated that the ranges of $\mathrm{P} / \mathrm{V}$ ratio for the intercalation-exfoliation-reduction catalysts synthesised using different mixture of solvent were in between 1.03 to 1.08. Even though the obtained values were slightly deviated from the nominal $\mathrm{P} / \mathrm{V}$ atomic ratio value of $1: 1$, these values indicated that the $\mathrm{V}^{4+}$ species that is 
TABLE 1: Specific BET surface area, chemical properties, average vanadium valence, and percentages of $\mathrm{V}^{4+}$ and $\mathrm{V}^{5+}$ oxidation states present in IER-VPD catalysts synthesized with different mixture of solvent.

\begin{tabular}{|c|c|c|c|c|c|}
\hline \multirow{2}{*}{ Catalysts } & \multirow{2}{*}{ Specific BET surface area $\left(\mathrm{m}^{2} / \mathrm{g}\right)$} & \multirow{2}{*}{ Atomic ratio $\mathrm{P} / \mathrm{V}$} & \multicolumn{3}{|c|}{ Oxidation of the vanadium } \\
\hline & & & $\mathrm{V}^{4+}(\%)$ & $\mathrm{V}^{5+}(\%)$ & $\mathrm{V}_{a v}$ \\
\hline IERC(2Bu-Et) & 11.7 & 1.08 & 74 & 26 & 4.26 \\
\hline IERC(2Bu-Et)RBi1 & 15.3 & 1.05 & 77 & 23 & 4.23 \\
\hline IERC(isoBu-Et) & 35.6 & 1.03 & 90 & 10 & 4.10 \\
\hline IERC(isoBu) & 21.8 & 1.05 & 93 & 7 & 4.07 \\
\hline
\end{tabular}

responsible for the activity of the respective catalyst could be stabilised by higher $\mathrm{P} / \mathrm{V}$ atomic ratio [1].

The average oxidation numbers of vanadium and percentage of $\mathrm{V}^{5+}$ and $\mathrm{V}^{4+}$ oxidation state are summarised in Table 1 . Doping 1\% of bismuth into the IER-VPD catalyst with the mixture of 2-butanol and ethanol has resulted in a slight decreased of the $\mathrm{V}^{5+}$ contribution from $26 \%$ to $23 \%$ for IERC(2Bu-Et) and IERC(2Bu-Et)RBil, respectively.

Moreover, changing the mixture solvent to isobutanol and ethanol also has caused remarkable lowering of $\mathrm{V}^{5+}$ phase to only $10 \%$ compared to $\operatorname{IERC}(2 \mathrm{Bu}-\mathrm{Et})$. Furthermore, the absence of ethanol with only the presence of isobutanol in the intercalation-exfoliation-reduction technique to synthesize the catalyst also caused a slight decrease in the formation of $\mathrm{V}^{5+}$ percentage to $7 \%$. The average oxidation state of vanadium reduced from 4.26 for $\operatorname{IERC}(2 \mathrm{Bu}-\mathrm{Et})$ to 4.23 , 4.10, and 4.07 for IERC(2Bu-Et)RBi1, IERC(isoBu-Et), and IERC(isoBu), respectively.

3.3. Scanning Electron Microscope (SEM). The surface morphologies of intercalation-exfoliation-reduction catalysts synthesized using different mixture of solvent were examined by using scanning electron microscope as shown in Figure 3. All the catalysts synthesised through intercalationexfoliation-reduction technique had lost their secondary structure of rosette shape and only consist of plate-like and rather flat crystal structure that these smaller platelets are unstable and have high surface energy, tendency to agglomerate, and are stacking with each other; hence, this caused a decrease of the surface area of the catalyst which is in agreement with the results obtained from the BET surface area measurements (Table 1).

3.4. Transmission Electron Microscope (TEM). Figure 4 shows the particle size of the intercalation-exfoliation-reduction VPD catalysts synthesized using different mixture of solvent which were examined by using TEM. The TEM images show that the IER-VPD catalysts synthesized indeed consist of nano crystallites with average sizes of approximately $20 \mathrm{~nm}$. These TEM images also further confirmed that these nanocrystallites are unstable, have high surface energy, tend to agglomerate, and stacking with each other to form larger platelets. This phenomenon will promote the decrease of the exposed surface to volume ratio to the surrounding environment that is causing the IER-VPD catalysts having a lower surface area which is also in agreement with the results obtained from the BET surface area measurements (Table 1).

3.5. Temperature-Programmed Reduction ( $T P R$ in $\mathrm{H}_{2} / \mathrm{Ar}$ ). Three distinct peak maxima exhibited by the IERC(2Bu-Et) catalyst were observed in the rate of hydrogen consumption at 802,984 and $1060 \mathrm{~K}$, respectively (Figure 5). The amount of oxygen removed by the reaction with $\mathrm{H}_{2}$ for this IER-VPD catalyst is $0.13 \times 10^{21}, 0.64 \times 10^{21}$, and $0.90 \times 10^{21}$ atoms g ${ }^{-1}$, respectively, with an oxygen ratio removed from $\mathrm{V}^{5+} / \mathrm{V}^{4+}$ of 0.08 (Table 2).

However, IERC(2Bu-Et)RBil, IERC(isoBu-Et), and IERC(isoBu) only show two distinct reduction peaks maxima in the rate of hydrogen consumption which is differ from IERC(2Bu-Et) catalyst produced. For the $1 \%$ bismuth-doped IER-VPD catalyst using mixture of 2-butanol and ethanol, IERC(2Bu-Et)RBil gave two reduction peaks whereby the first reduction peak occurred at slightly higher temperature compared to the undoped VPO catalyst using the same mixture of solvent which is $829 \mathrm{~K}$ with $0.13 \times 10^{21}$ atoms $\mathrm{g}^{-1}$ of the amount of oxygen removed at that particular peak.

Interestingly, the addition of $1 \%$ bismuth significantly lowered the second reduction peak to $941 \mathrm{~K}$ with higher amount of oxygen removed $\left(1.55 \times 10^{21}\right.$ atoms $\left.\mathrm{g}^{-1}\right)$. The bismuth-doped VPO catalyst shows the same oxygen ratio removed from $\mathrm{V}^{5+} / \mathrm{V}^{4+}$ in undoped catalyst produced using the same mixture of solvent. The lowering of the reduction peak temperature and the increment of the oxygen atoms removed from the lattice by the reaction of $\mathrm{H}_{2}$ may suggest that the oxygen species in the bismuth which promoted VPO catalyst are more reactive and will give higher conversion for $n$-butane oxidation compared to the unpromoted VPO catalyst.

Another noteworthy point is that, by changing the mixture solvent from 2-butanol and ethanol to isobutanol and ethanol in the same technique to produce the VPO catalyst, IERC(isoBu-Et) shows the first reduction peak occurred at relative higher temperature which is $895 \mathrm{~K}$ but with a slight increase in the amount of oxygen removed that is $0.14 \times$ $10^{21}$ atoms $^{-1}$ compared to $\operatorname{IERC}(2 \mathrm{Bu}-\mathrm{Et})$. However, the second reduction peak of IERC(isoBu-Et) somehow occurred at lower temperature $(1030 \mathrm{~K})$ but with a lower amount 


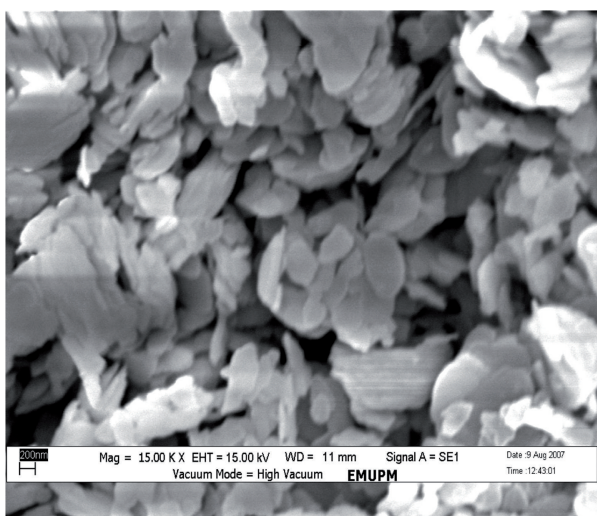

(a)

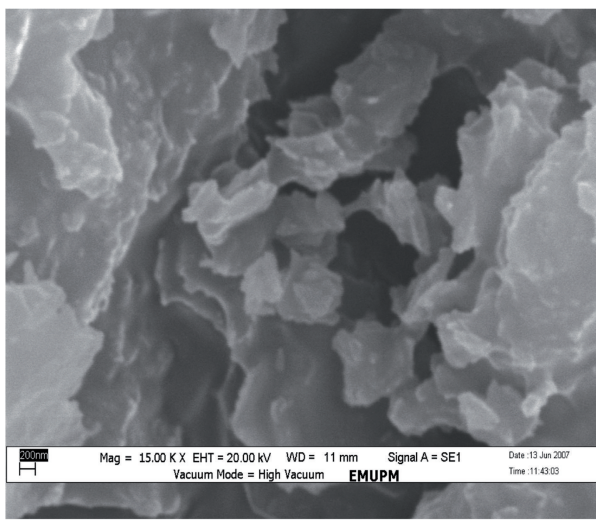

(c)

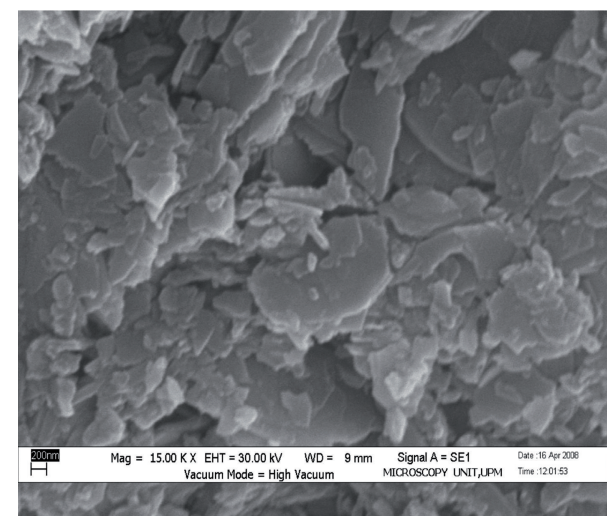

(b)

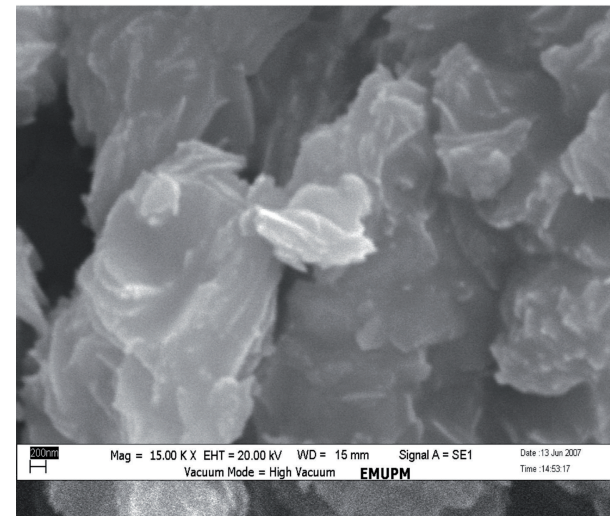

(d)

Figure 3: SEM micrographs of (a) IERC(2Bu-Et), (b) IERC(2Bu-Et)RBil, (c) IERC(isoBu-Et), and (d) IERC(isoBu) (with 15000x magnification).

TABLE 2: Total amount of oxygen removed from the doped and undoped IER-VPD catalysts by reduction in $\mathrm{H}_{2} / \mathrm{Ar}$.

\begin{tabular}{|c|c|c|c|c|}
\hline Catalyst (Peak) & $T_{\max }(\mathrm{K})$ & $\begin{array}{l}\text { Oxygen atom } \\
\text { removed } \\
\left(\times 10^{-3} \mathrm{~mol} \mathrm{~g}^{-1}\right) \\
\end{array}$ & $\begin{array}{c}\text { Oxygen atom } \\
\text { removed } \\
\left(\times 10^{21} \text { atoms } g^{-1}\right)\end{array}$ & $\begin{array}{l}\text { Ratio for oxygen } \\
\text { removal of } \mathrm{V}^{++} / \mathrm{V}^{4+}\end{array}$ \\
\hline \multicolumn{5}{|l|}{ IERC(2Bu-Et) } \\
\hline 1 & 802 & 0.22 & 0.13 & \multirow{3}{*}{0.08} \\
\hline 2 & 984 & 1.06 & 0.64 & \\
\hline 3 & 1060 & 1.50 & 0.90 & \\
\hline Total oxygen atoms removed & & 2.78 & 1.67 & \\
\hline \multicolumn{5}{|l|}{ IERC(2Bu-Et)RBi1 } \\
\hline 1 & 829 & 0.21 & 0.13 & \multirow{3}{*}{0.08} \\
\hline 2 & 941 & 2.57 & 1.55 & \\
\hline Total oxygen atoms removed & & 2.78 & 1.68 & \\
\hline \multicolumn{5}{|l|}{ IERC(isoBu-Et) } \\
\hline 1 & 895 & 0.24 & 0.14 & \multirow{3}{*}{0.17} \\
\hline 2 & 1030 & 1.99 & 1.20 & \\
\hline Total oxygen atoms removed & & 2.23 & 1.34 & \\
\hline \multicolumn{5}{|l|}{ IERC(isoBu) } \\
\hline 1 & 890 & 0.28 & 0.17 & \multirow{3}{*}{0.12} \\
\hline 2 & 1059 & 2.42 & 1.46 & \\
\hline Total oxygen atoms removed & & 2.70 & 1.63 & \\
\hline
\end{tabular}




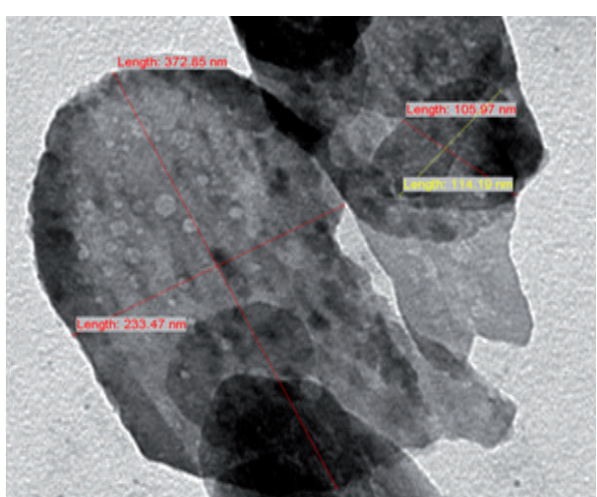

(a) Approximate $100 \mathrm{~nm}$

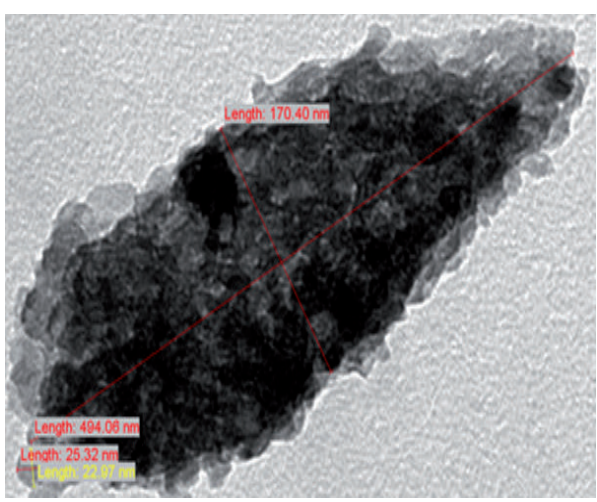

(c) Approximate $25 \mathrm{~nm}$

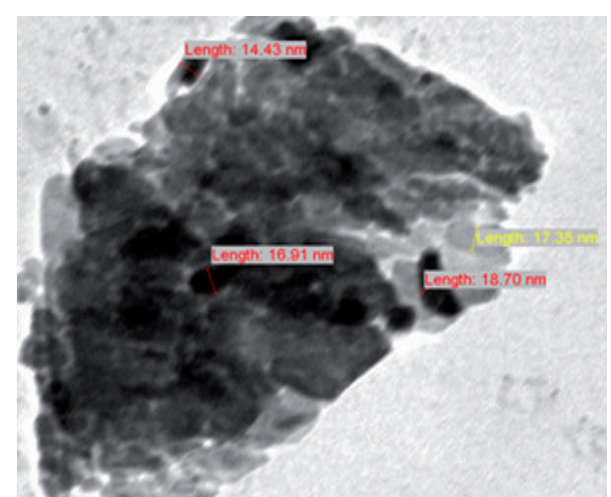

(b) Approximate $20 \mathrm{~nm}$

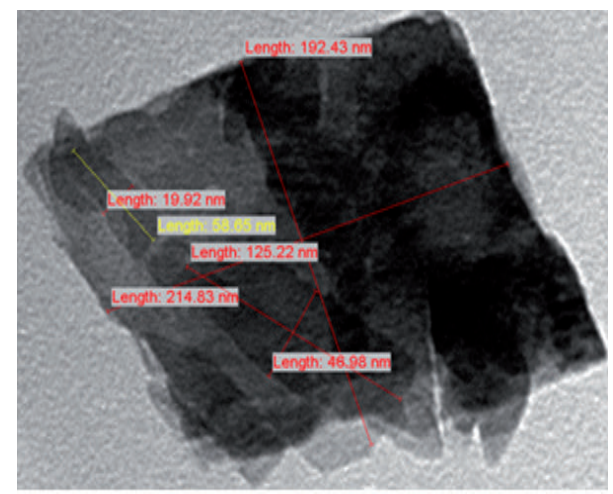

(d) Approximate $60 \mathrm{~nm}$

Figure 4: TEM micrographs of (a) IERC(2Bu-Et), (b) IERC(2Bu-Et)RBi1, (c) IERC(isoBu-Et), and (d) IERC(isoBu).

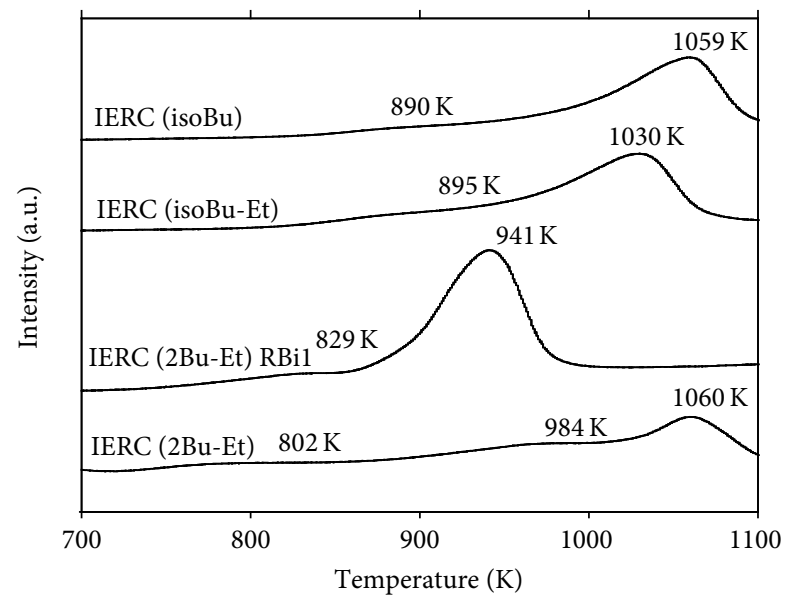

FIGURE 5: TPR profiles for the IER-VPD catalysts.

of oxygen removed which is $1.20 \times 10^{21}$ atoms $\mathrm{g}^{-1}$ with an oxygen ratio removed from $\mathrm{V}^{5+} / \mathrm{V}^{4+}$ of 0.17 as shown in Table 2.

Nevertheless, with the absence of ethanol in the same preparation technique to produce IERC(isoBu) catalyst, the first reduction peak occurred at slightly lower temperature which is $890 \mathrm{~K}$ but with a slight increase in the amount of oxygen removed which is $0.17 \times 10^{21}$ atoms $g^{-1}$, and

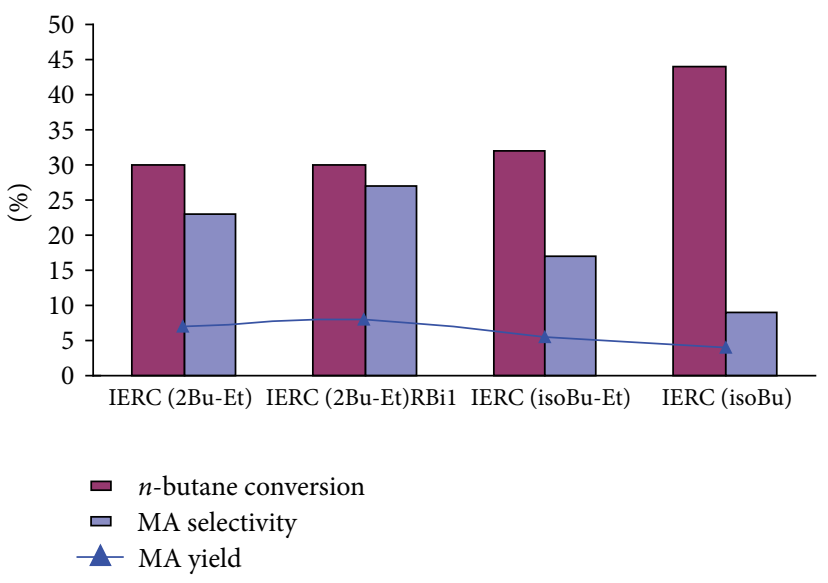

FIGURE 6: The relation between conversion (\%), MA selectivity (\%), and MA yield (\%) of catalysts produced in $n$-butane oxidation.

the second reduction peak occurred at higher temperature $(1059 \mathrm{~K})$ but with a higher amount of oxygen removed which is $1.46 \times 10^{21}$ atoms $\mathrm{g}^{-1}$ compared to IERC(isoBu-Et).

3.6. Catalytic Oxidation of $n$-Butane. As depicted from Figure 6, IERC $(2 \mathrm{Bu}-\mathrm{Et}) \mathrm{RBil}$ is the most selective catalyst with $27.0 \%$ of MA selectivity, followed by IERC(2Bu-Et) 
TABLE 3: The catalytic performance of doped and undoped intercalation-exfoliation-reduction catalysts using different mixture of solvent for oxidation of $n$-butane.

\begin{tabular}{|c|c|c|c|c|c|}
\hline \multirow{2}{*}{ Catalysts } & \multirow{2}{*}{$n$-Butane conversion (\%) } & \multicolumn{3}{|c|}{ Product selectivity (\%) } & \multirow{2}{*}{ MA yield (\%) } \\
\hline & & MA & $\mathrm{CO}$ & $\mathrm{CO}_{2}$ & \\
\hline IERC(2Bu-Et) & 30.0 & 23.0 & 3.0 & 74.0 & 6.9 \\
\hline IERC(2Bu-Et)RBi1 & 30.0 & 27.0 & 8.0 & 65.0 & 8.1 \\
\hline IERC(isoBu-Et) & 32.0 & 17.0 & 37.0 & 46.0 & 5.4 \\
\hline IERC(isoBu) & 44.0 & 9.0 & 41.0 & 50.0 & 4.0 \\
\hline
\end{tabular}

(23.0\%), IERC(isoBu-Et) (17.0\%), and IERC(isoBu) (9.0\%). Furthermore, IERC(isoBu) with $44.0 \%$ conversion was also found to be the most active catalyst, followed by IERC(isoBuEt) $(32.0 \%)$, IERC(2Bu-Et), and IERC(2Bu-Et)RBil both catalysts showing the same amount of conversion (19.2\%) as summarised in Table 3.

The difference in catalytic activity and selectivity for the doped and undoped VPO catalysts which undergo intercalation-exfoliation-reduction technique using different mixture of solvent is attributed to the higher reactivity of the oxygen species in the lattice. It should be noted that IERC $(2 \mathrm{Bu}-\mathrm{Et}) \mathrm{RBil}$ catalyst shows the additional formation of crystalline $\mathrm{V}^{5+}$ phase component in the XRD analysis. As reported earlier, selective oxidation of $n$-butane over VPO catalyst was shown to proceed via a redox mechanism [14]. Therefore, the reduction behaviour of the synthesised catalyst is a reliable method as an indicator for the catalytic performance.

As expected earlier, IERC (2Bu-Et)RBil catalyst gave the highest MA selectivity due to reactive $\mathrm{O}^{2-}$ species released from the additional crystalline $\mathrm{V}^{5+}$ phase formed $\left(\mathrm{O}^{2-}-\mathrm{V}^{5+}\right.$ pair) at relative lower temperature. Furthermore, IERC $(2 \mathrm{Bu}-$ Et) catalyst also gave relatively high MA selectivity due to the additional reactive and mobile $\mathrm{O}^{2-}$ species released at lower temperature. Moreover, IERC(isoBu) catalysts gave the highest activity due to high amount of reactive $\mathrm{O}^{-}$species released from $\mathrm{V}^{4+}$ phase $\left(\mathrm{O}^{-}-\mathrm{V}^{4+}\right.$ pair) whereby this catalyst consists of high percentage of $\mathrm{V}^{4+}(93 \%)$.

\section{Conclusions}

All the catalysts synthesized through intercalation-exfoliation-reduction technique had lost their secondary structure of rosette-shape and only consist of plate-like and rather flat crystal structure that these smaller platelets are unstable, have high surface energy and tendency to agglomerate, and are stacking with each other which is in agreement with the TEM images. Moreover, IERC(2Bu-Et)RBil catalyst gave the highest MA selectivity due to reactive $\mathrm{O}^{2-}$ species released from the additional crystalline $\mathrm{V}^{5+}$ phase formed by doping $1 \%$ bismuth as promoter $\left(\mathrm{O}^{2-}-\mathrm{V}^{5+}\right.$ pair $)$ at relative lower temperature. Nevertheless, IERC(isoBu) catalysts gave the highest activity due to high amount of reactive $\mathrm{O}^{-}$ species released from $\mathrm{V}^{4+}$ phase $\left(\mathrm{O}^{-}-\mathrm{V}^{4+}\right.$ pair) whereby the
IERC(isoBu) catalyst synthesised consists of high percentage of $\mathrm{V}^{4+}(93 \%)$.

\section{References}

[1] A. A. Rownaghi, Y. H. Taufiq-Yap, and F. Rezaei, "Innovative process for the synthesis of vanadyl pyrophosphate as a highly selective catalyst for $n$-butane oxidation," Chemical Engineering Journal, vol. 165, no. 1, pp. 328-335, 2010.

[2] G. Centi, F. Cavani, and F. Trifirò, Selective Oxidation by Heterogeneous Catalysis, Kluwer Academic; Plenum Publisher, New York, NY, USA, 2001.

[3] G. J. Hutchings, "Vanadium phosphate: a new look at the active components of catalysts for theoxidation of butane to maleic anhydride," Journal of Materials Chemistry, vol. 14, pp. 3385-3395, 2004.

[4] H. Imai, Y. Kamiya, and T. Okuhara, "Selective oxidation of $n$ butane over nanosized crystallites of $(\mathrm{VO})_{2} \mathrm{P}_{2} \mathrm{O}_{7}$ synthesized by an exfoliation-reduction process of $\mathrm{VOPO}_{4} \cdot 2 \mathrm{H}_{2} \mathrm{O}$ in a mixture of 2-butanol and ethanol," Journal of Catalysis, vol. 251, no. 1, pp. 195-203, 2007.

[5] T. Okuhara, K. Inumaru, and M. Misono, Catalytic Selective Oxidation, Edited by J. Hightower and T. Oyama, American Chemical Society, Washingon, DC, USA, 1993.

[6] E. Bordes, in Structure-Activity and Selectivity Relationships inHeterogeneous Catalysis, R. K. Grasselli and A. W. Sleight, Eds., p. 21, Elsevier, Amsterdam, The Netherlands, 1991.

[7] P. A. Agaskar, L. De Caul, and R. K. Grasselli, "A molecular level mechanism of $n$-butane oxidation to maleic anhydride over vanadyl pyrophosphate," Catalysis Letters, vol. 23, no. 3-4, pp. 339-351, 1994.

[8] M. Niwa and Y. Murakami, "Reaction mechanism of ammoxidation of toluene. IV. Oxidation state of vanadium oxide and its reactivity for toluene oxidation," Journal of Catalysis, vol. 76, no. 1, pp. 9-16, 1982.

[9] C. J. Kiely, S. Sajip, I. J. Ellison, M. T. Sananes, G. J. Hutchings, and J. C. Volta, "Electron microscopy studies of vanadium phosphorus oxide catalysts derived from $\mathrm{VOPO}_{4} \cdot 2 \mathrm{H}_{2} \mathrm{O}$," Catalysis Letters, vol. 33, no. 3-4, pp. 357-368, 1995.

[10] G. J. Hutchings and R. Higgins, "Selective oxidation of $n$-butane to maleic anhydride with vanadium phosphorus catalysts prepared by comminution in the presence of dispersants," Applied Catalysis A, vol. 154, no. 1-2, pp. 103-115, 1997.

[11] Y. Kamiya, N. Ryumon, H. Imai, and T. Okuhara, "Nanosized crystallites of vanadyl pyrophosphate as a highly selective catalyst for $n$-butane oxidation," Catalysis Letters, vol. 111, no. 3-4, pp. 159-163, 2006. 
[12] Y. H. Taufiq-Yap, Y. Kamiya, and K. P. Tan, "Promotional effect of bismuth as dopant in bi-doped vanadyl pyrophosphate catalysts for selective oxidation of $n$-butane to maleic anhydride," Journal of Natural Gas Chemistry, vol. 15, no. 4, pp. 297-302, 2006.

[13] G. W. Coulston, S. R. Bare, H. Kung et al., "The kinetic significance of $\mathrm{V}^{5+}$ in $n$-butane oxidation catalyzed by vanadium phosphates," Science, vol. 275, no. 5297, pp. 191-193, 1997.

[14] P. Mars and D. W. Van Krevelen, "Oxidations carried out by means of vanadium oxide catalysts," Chemical Engineering Science, vol. 3, supplement 1, pp. 41-59, 1954. 

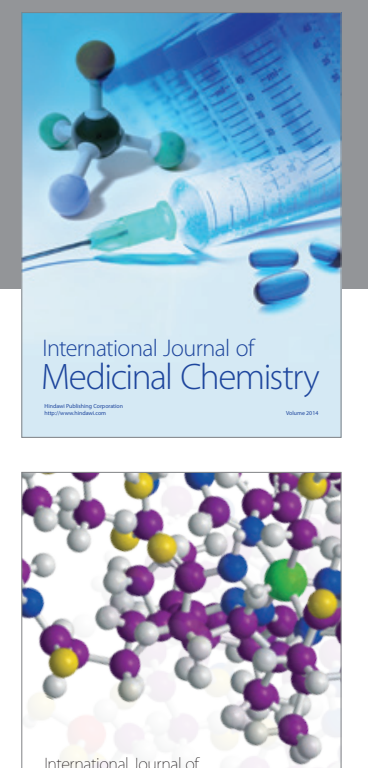

\section{Carbohydrate} Chemistry

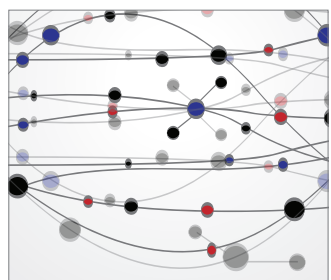

The Scientific World Journal
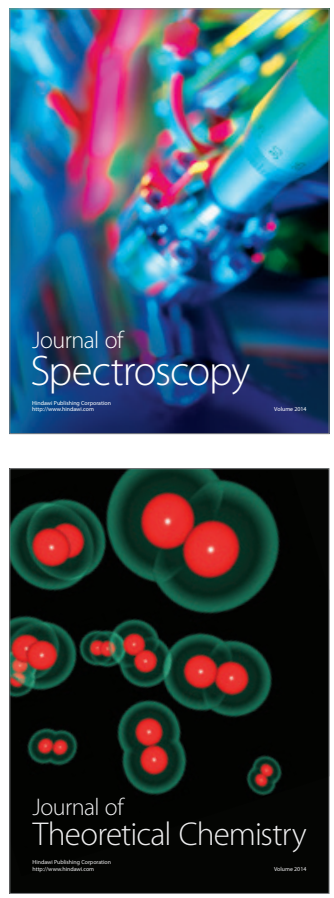
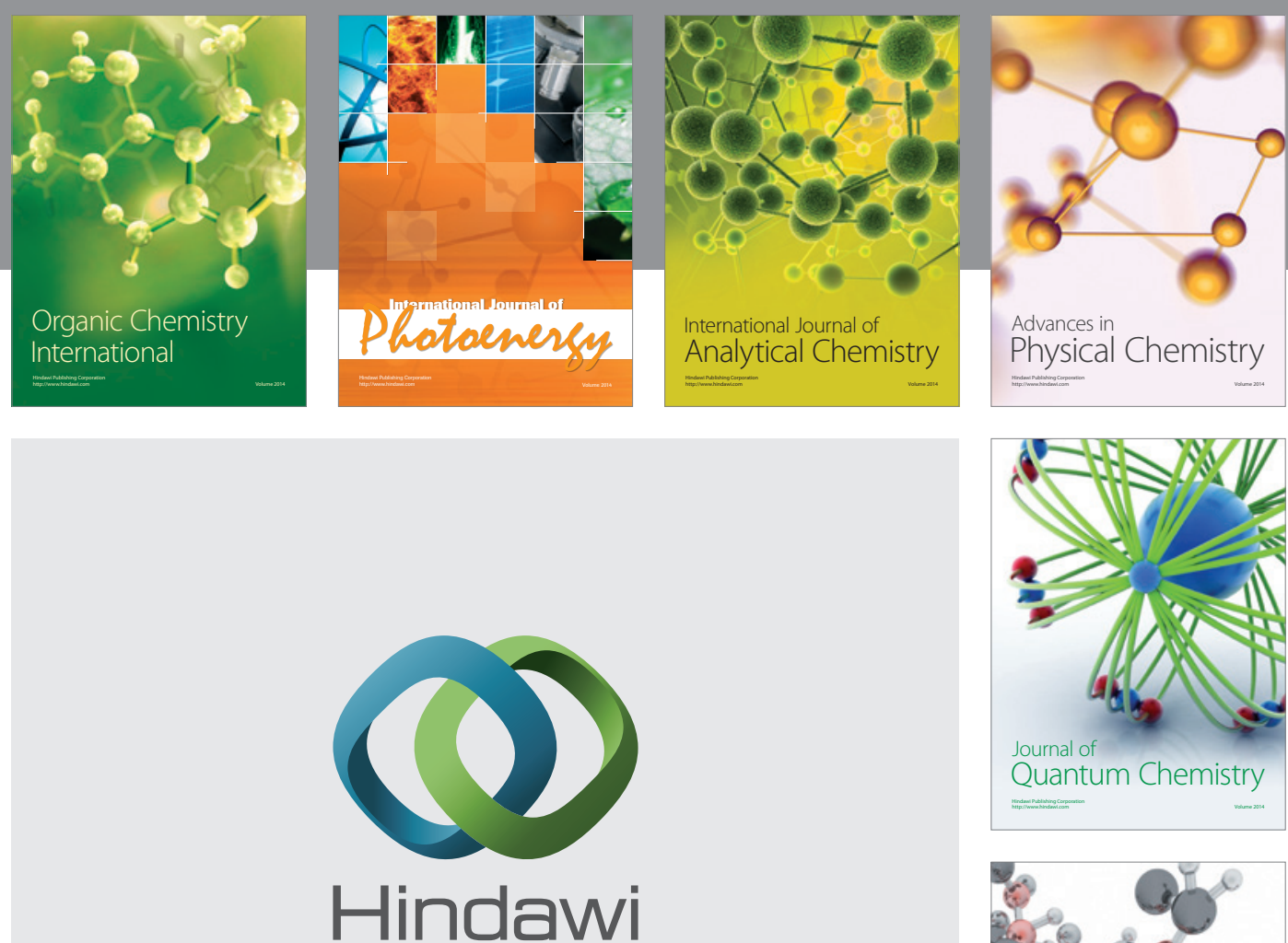

Submit your manuscripts at

http://www.hindawi.com

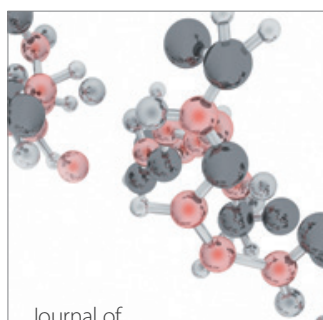

Analytical Methods

in Chemistry

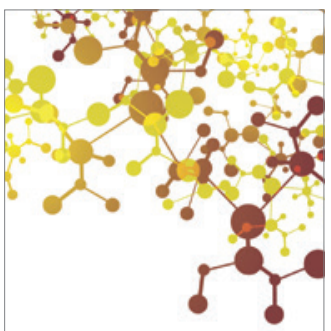

Journal of

Applied Chemistry

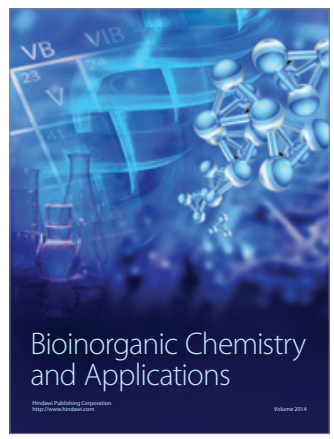

Inorganic Chemistry
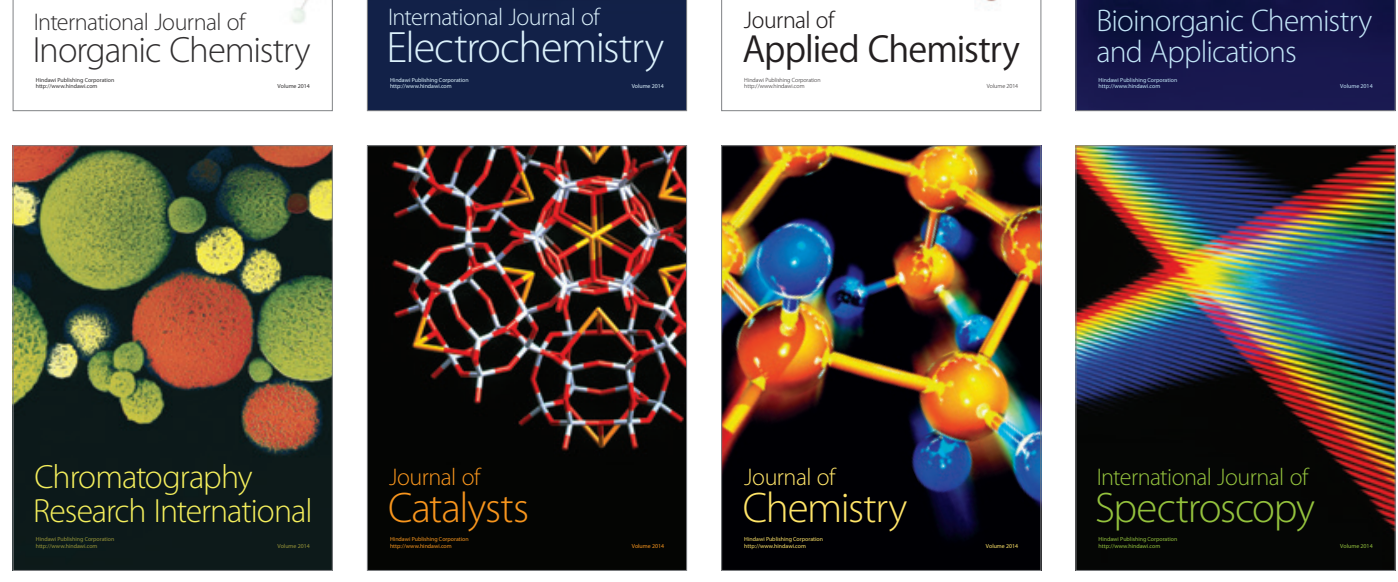